\title{
Renovação e Gestão de cidades: Experiências Participativas no Centro Histórico de São Paulo
}

\author{
Sirlei Pitteri e Priscila Perazzo ${ }^{1}$
}

RESUMO: A questão dos centros metropolitanos ganha importância cada vez maior para as nações nesta virada de milênio. Os projetos de revalorização das áreas centrais das cidades transformaram-se em uma das funções básicas dos governos, pelo consenso de que as cidades representariam possíveis plataformas de desenvolvimento econômico e promoção da inclusão social mediante a geração de empregos e de renda. Essa abordagem sugere uma reflexão sobre o dilema do desenvolvimento urbano x inclusão social, enorme desafio diante das tendências excludentes, cada vez mais acentuadas, em especial nos países emergentes. A integração entre as esferas pública e privada em experiências participativas é outra questão a avaliar, principalmente em sociedades com processos democráticos ainda não totalmente consolidados. O presente estudo tem por objetivo analisar as experiências participativas de renovação e gestão do Centro Histórico de São Paulo por meio dos projetos estratégicos, seus desdobramentos e resultados, sob a ótica das organizações contemporâneas, com destaque para as ações coletivas e o exercício da cidadania.

Palavras-chave: experiências participativas, renovação de cidades, gestão de cidades, Centro Histórico de São Paulo.

ABSTRACT: The issue of metropolitan town centres has grown more and more important in the last years, with projects to renovate town centre areas assuming particular significance for public administration, the more so because then likely represent a platform for the economic development and social inclusion through the offering of jobs and the generation of revenues. Such an approach invites for a reflexion about the dilemma urban development $x$ social inclusion - a challenge facing the excluding trends haunting especially developing nations. The integration of private and public sectors in participative experiments is yet another issue worth examining, mainly in societies where democracy is still not consolidated. This study purposes to analyse the participative experiments in the plan for the renovation and administration of São Paulo historic town centre by assessing the joint estrategic projects, their unfolding and outcomes, in the view of contemporary organizations, with special attention to collective actions and the practice of citizenship.

KEY WORDS: participative experiments, town centres renewal, town centres management, São Paulo historic town centre.

\footnotetext{
${ }^{1}$ Sirlei Pitteri. Mestre em Administração. Programa de Mestrado em Administração - Universidade IMES - São Caetano do Sul - SP. Rua Pensilvânia, 742 - apto 42 .CEP 04564-002 - São Paulo - SP. sirlei_pitteri@uol.com.br

Priscila Perazzo. Doutora em História. Professora da disciplina Cidades, Política e Memória, do Programa de Mestrado em Administração - Universidade IMES - São Caetano do Sul - SP.Rua Vitória Regia, 100 09080-320 - Santo André SP.prisperazzo@ig.com.br
} 


\section{Introdução}

As primeiras percepções sobre as recentes transformações urbanísticas por que passa o Centro Histórico $^{2}$ da cidade de São Paulo sugerem algumas semelhanças com as imagens oficiais de um sem número de metrópoles em todos os continentes. Os projetos urbanísticos atuais apresentam uma estética voltada ao embelezamento das cidades, por meio da reurbanização de áreas degradadas e, atenção especial tem sido dada aos centros das cidades, onde se promovem a renovação de edifícios históricos e a criação de novos espaços de cultura, diversão e lazer.

Segundo Borja (1996), o século XX foi o século das cidades, mas o século XXI será urbano: "o progresso econômico, o bem-estar-social e a integração cultural dos povos determinar-se-ão, em grande parte, nas cidades". Mário Covas, ex-governador do estado de São Paulo, lembrava que no Brasil de hoje, como no de ontem, os municípios desempenham papel semelhante na formação dos primeiros alicerces da unidade nacional e a primeira base de desenvolvimento, pois “é nas cidades que tudo se dá: as oportunidades de trabalho e de lazer, a difusão da educação e da cultura, o exercício mais imediato da cidadania" (COVAS, 1999, p.3).

Parece haver um paradoxo entre a importância das cidades no novo ambiente de conectividade global, ou seja, a globalização que maximiza o uso e o poder dos fluxos intangíveis e parece não valorizar o espaço físico. Então, para que cidades? Wilheim (2005) acredita que a vida do século XXI poderá vir a se caracterizar por um novo Humanismo, ou seja, um Renascimento em que as pessoas aprenderão a transformar informação em conhecimento, multidisciplinaridade em transversalidade, neoliberalismo econômico em pós-capitalismo social, trabalho em realização, hierarquias em redes, exclusão social em inclusão, injustiças contra a mulher em valorização das diferenças de gênero. E essas transformações ocorrerão nas cidades, pois é nelas que se dá o processo de transformação, a geração de uma sociedade justa e de uma res publica ${ }^{3}$ apropriada por todos.

\footnotetext{
${ }^{2}$ O Centro Histórico de São Paulo foi delimitado pelo Decreto municipal $\mathrm{n}^{\circ} 46.507$, de 17 de outubro de 2005, contemplando os os subdistritos Sé e República.

${ }^{3}$ Res pública no sentido estrito senso, efetivamente como coisa pública, de todos e para todos. Origem do termo república, sistema político no Brasil desde 1889. Designa o estoque de ativos e o fluxo de recursos que o Estado e as entidades públicas não-estatais controlam.
} 
Com relação às transformações urbanísticas no Centro Histórico de São Paulo, Campos (2002) aponta para alguns dilemas da globalização e salienta a contradição existente no processo de inserção da metrópole paulistana na economia globalizada, pelo modelo de cidade mundial terciarizada e centralizadora das redes de informação, enquanto não se atacam os problemas de exclusão social, de renovação das áreas centrais e a busca da qualidade de vida urbana. A conclusão de Campos sugere uma nova atuação dos poderes públicos e da iniciativa privada a fim de se inverter as prioridades na solução dos problemas que, desde 1930, reafirmam o enfoque no sistema viário como solução para as questões paulistanas. Em resposta a esse dilema, percebe-se no Centro Histórico de São Paulo um intenso movimento de recuperação de estações ferroviárias e edifícios degradados, intervenções urbanísticas em praças, parques e viadutos, resultado da articulação entre governos estadual e municipal, empresas, entidades e representantes da sociedade civil.

Levantamentos preliminares indicam que a intensificação de parcerias entre empresas, governos estadual e municipal, organizações não-governamentais e outros setores da sociedade que atuam no Centro Histórico de São Paulo são os principais promotores das ações que começam a ser percebidas pela população paulistana, nesse início de século XXI. A organização não-governamental (ONG), Associação Viva o Centro, formada em 1991, foi a primeira entidade constituída com a finalidade de promover o desenvolvimento da área central e tem sido um importante catalisador, tanto para a execução dos projetos urbanísticos, como na articulação entre governos e sociedade, a fim de criar soluções aos problemas do dia-a-dia.

Os projetos - São Paulo: Uma Nova Abordagem (1991-2000), Ações Locais (1995-atual) e Ação Centro (2003-atual) - são as principais referências sobre as experiências participativas que vêm sendo conduzidas no Centro Histórico de São Paulo. O primeiro é o resultado de nove anos de estudos sobre os principais problemas recorrentes na área central, caracterizados principalmente pela degradação ambiental provocada pela desocupação de edifícios e a transformação do espaço público em abrigos para a população excluída. Paralelamente aos grandes projetos de recuperação de praças, estações e edifícios, observou-se a necessidade de melhorar a gestão no entorno, o que envolveria a participação de todos os usuários do Centro Histórico. Assim, foi iniciado o programa de Ações Locais, 
em 1995, que dividiu a área central em 50 micro-regiões e em cada uma delas incentivou a formação de núcleos constituídos por moradores e usuários, a fim de se desenvolver uma gestão compartilhada dos espaços públicos. O poder público municipal também vem adotando políticas convergentes a essas iniciativas, como a descentralização da gestão pública, em 2002, por meio da criação de 31 subprefeituras que substituíram as administrações regionais e incorporaram funções das secretarias e investimentos e ampliações das áreas da cultura, lazer e turismo. A criação do programa Ação Centro (2003), por iniciativa da Prefeitura Municipal de São Paulo em parceria com a sociedade civil, é o projeto mais recente e tem como objetivo reverter o processo de degradação e desvalorização afetiva do Centro Histórico.

O crescimento de organizações privadas sem fins lucrativos é um fenômeno mundial e marca a transição para o século XXI, pela percepção da sociedade que o modelo dualista governos e empresas - é insuficiente para solucionar os problemas contemporâneos. Assim como os governos estão desenvolvendo um caráter mais empreendedor, as empresas estão se tornando mais sensíveis com as questões ambientais. Os critérios de avaliação do sucesso empresarial começam a incorporar valores organizacionais que estão além da sustentação econômica e lucro financeiro. Dizem respeito também à preservação ambiental e à qualidade de vida. Cappellin (2002) lembra que entidade empresarial de sucesso é aquela que sabe sintonizar-se com seu entorno e catalisar esforços da sociedade a fim de solucionar os problemas locais. Atualmente estão se formando, nas localidades onde as empresas se constituem, as corporações não-lucrativas cuja finalidade primordial é promover benefícios coletivos ${ }^{4}$. A transposição do conceito de ações coletivas das grandes organizações para o cenário das cidades é justificável pelo fato de que o discurso contemporâneo sobre os novos arranjos nas organizações e instituições aplica-se às cidades, pois, ao se olhar para uma cidade como uma organização, percebem-se idéias e metáforas pelos traços distintos de complexidade, diversidade, contradição e ambigüidades que ambas possuem (FISCHER, 1996).

A complexidade do ambiente organizacional contemporâneo, colocado nessa perspectiva, evidencia duas possíveis vertentes: a primeira se situa no dilema da renovação de cidades

\footnotetext{
4 "Os benefícios coletivos, por natureza e característica, são indivisíveis e generalizados, devendo abranger todos os membros de uma organização independentemente de sua participação no processo que levou à conquista de benefícios” (OLSON, 1971, p.18).
} 
sob a lógica do desenvolvimento urbano que promoveria a inclusão social por meio da geração de emprego e renda. Esse tem sido o grande desafio das metrópoles, em especial nos países emergentes, onde as tendências excludentes têm sido cada vez mais acentuadas nos últimos trinta anos. A segunda vertente se relaciona com a integração entre as esferas pública e privada na gestão das cidades. No Brasil, esse processo é muito recente e está intimamente relacionado ao desenvolvimento da democracia, que sofreu forte ingerência de regimes autoritários e centralizadores e com predominância da tradição paternalista ao longo de quase toda a sua história.

As primeiras indagações surgem a partir da tomada de decisão sobre os projetos que vêm sendo desenvolvidos: O que motiva a escolha dos projetos? A tomada de decisão envolve quais segmentos da sociedade? Os projetos visam o benefício da sociedade através de iniciativas não-públicas? Seriam essas ações capazes de aproximar diferentes setores do governo, a fim de racionalizar e otimizar recursos para executá-las? Esses processos estariam contribuindo para que a população adquira empowerment ${ }^{5}$ a fim de atuar e transformar efetivamente suas vidas e de seus ambientes? Como ocorre o exercício da cidadania $^{6}$ a partir da implementação desses projetos? Nesse sentido, de forma geral, pergunta-se: Como ocorrem as experiências participativas para a gestão do Centro Histórico de São Paulo, na perspectiva de uma melhor competitividade da cidade de São Paulo, no cenário globalizado? Tendo em vista tais indagações, esse estudo tem como objetivo geral analisar os projetos desenvolvidos e articulados pela Associação Viva o Centro, na década de 1990, como experiências participativas para a gestão do Centro Histórico de São Paulo. Atualmente, essas questões se justificam, pois, os processos de renovação de cidades vêm movimentando setores públicos e privados em um sem número de localidades, que partem de experiências participativas com o objetivo de promover o desenvolvimento urbano para erradicar a pobreza, promover a preservação ambiental e criar condições para o desenvolvimento sustentável das localidades, o que pode ser traduzido em inclusão social.

\footnotetext{
${ }^{5}$ A expressão empowerment é comumente utilizada em inglês e deve ser entendida como ganho de poder político da sociedade.

${ }^{6}$ Cidadania, nesse contexto, deve ser entendida como a atitude que leva o indivíduo a se afirmar na sociedade, por meio da aquisição de direitos e sua capacidade de proposição e execução de ações intersetoriais que se traduzam em melhorias da qualidade de vida, individual e coletiva dos moradores e usuários, e da qualidade ambiental das localidades.
} 


\section{Método}

Esta pesquisa foi, fundamentalmente, qualitativa. Para se elaborar a pesquisa exploratória, optou-se pela abordagem sistêmica, focalizando o Centro Histórico de São Paulo e a adoção do quadro de análise de Cidades Estratégicas de Borja (1996) como referência para a sistematização das análises das principais percepções obtidas, de modo a autenticar os significados entre o referencial teórico e os fatos da realidade. Os três projetos São Paulo Centro: Uma Nova Abordagem, Ações Locais e Ação Centro foram estudados por meio de pesquisas bibliográfica e documental e validados por meio de observação direta e participante, coleta de depoimentos de autoridades, jornalistas, profissionais e especialistas envolvidos, moradores, comerciantes, usuários e outros. Os procedimentos para coleta de informações se concentraram em verificar se as experiências participativas convergem com o quadro de referência proposto por Borja (1996), conforme Quadro 1, a seguir:

\section{Quadro 1}

\begin{tabular}{|c|c|}
\hline DIMENSÃO & DESAFIOS \\
\hline $\begin{array}{l}\text { ECONÔMICA } \\
\text { Os projetos apresentam evidências sobre a } \\
\text { capacidade de reativação das bases } \\
\text { produtivas nas localidades? }\end{array}$ & $\begin{array}{l}\text { NOVA BASE ECONÔMICA } \\
\text { Como estão sendo constituídas as novas bases econômicas no Centro Histórico de São Paulo? } \\
\text { INFRA-ESTRUTURA URBANA } \\
\text { Qual a adequação da infra-estrutura urbana das localidades dos projetos e que medidas estão } \\
\text { sendo adotadas para harmonizar os recursos existentes, as funcionalidades dos mesmos e as } \\
\text { estratégias propostas? }\end{array}$ \\
\hline $\begin{array}{l}\text { SOCIAL } \\
\text { Existe integração efetiva entre as esferas } \\
\text { públicas e a sociedade? As experiências } \\
\text { participativas estão contribuindo para que } \\
\text { a população adquira empowerment? A } \\
\text { cidadania, que se exerce nos ambientes } \\
\text { renovados, aproxima-se dos conceitos } \\
\text { propostos para este estudo? }\end{array}$ & $\begin{array}{l}\text { QUALIDADE DE VIDA } \\
\text { Como os usuários, servidores públicos, empresários e moradores das áreas que estão sofrendo } \\
\text { intervenções urbanísticas percebem a qualidade de vida e a integração social? } \\
\text { INTEGRAÇÃO SOCIAL } \\
\text { Como os usuários, servidores públicos, empresários e moradores das áreas que estão sofrendo } \\
\text { intervenções urbanísticas percebem a qualidade de vida e a integração social? }\end{array}$ \\
\hline $\begin{array}{l}\text { POLÍTICA } \\
\text { Os poderes públicos criam incentivos que } \\
\text { complementem as dimensões anteriores? }\end{array}$ & $\begin{array}{l}\text { GOVERNABILIDADE } \\
\text { Quais as medidas que estão sendo adotadas para viabilizar a governabilidade do Centro } \\
\text { Histórico de São Paulo? }\end{array}$ \\
\hline
\end{tabular}

Quadro de referência de Cidades Estratégicas de Borja (1996).

O conceito de Cidades Estratégicas, na concepção de Borja (1996), está intimamente relacionado às novas competências, novos recursos e novos modelos de gestão a serem adotados nas cidades. Entende-se a cidade não só como um território que concentra um importante grupo humano e uma grande diversidade de atividades, mas também como um espaço simbiótico, entre poder político e sociedade civil, e simbólico, que integra 
culturalmente e confere identidade coletiva aos seus habitantes. A cidade transforma-se, portanto, em um campo de respostas possíveis aos desafios econômicos, políticos e culturais de nossa época. O objetivo principal é encontrar respostas integradas, e não setoriais, para os problemas de emprego, educação, cultura, moradia e transportes. O estabelecimento de compromissos públicos-privados para o crescimento econômico e preservação do meio ambiente, configurando novos espaços e mecanismos que estimulem a participação política e facilitem a relação entre a administração e os administradores são respostas que tendem a concretizar-se na definição de um projeto futuro para as cidades.

Embora novos imperativos do planejamento urbano se façam presentes, a desigualdade social não tem sido a questão central, na opinião de Sanchez (2003), pois, os projetos estratégicos em torno das cidades vêm transformando a esfera política local apenas em espaço do exercício de um projeto mercadológico, associando pautas para as reformas pública e administrativa dos governos à realização de mega-eventos de caráter internacional.

Rattner (2002) lembra que a inclusão social e o exercício da cidadania tornam-se viáveis somente quando, pela participação em ações coletivas, os excluídos são capazes de recuperar sua dignidade e conseguem - além de emprego e renda - acesso à moradia decente, facilidades culturais e serviços sociais, como educação e saúde. Exercitar a cidadania ultrapassa o âmbito estreito dos programas de filantropia e exige o engajamento contínuo do poder público através de políticas pró-ativas e preventivas, sobretudo na área econômica. De acordo com Borja (1996), os projetos estratégicos que pretendem dar visibilidade às cidades para os investidores externos devem levar os atores públicos e privados dominantes a entender que é pouco viável aquela cidade que exclui ou marginaliza parte importante de sua população ou que lhe impõe uma condição de vida difícil de suportar. Questões como trabalho infantil, economia informal, pobreza e outros problemas enraizados no centro das cidades decorrem, sobretudo de processos de exclusão social cada vez mais acentuados pelas políticas econômicas dominantes nos tempos atuais.

Nas metrópoles dos países emergentes, onde os processos de industrialização ocorreram tardiamente, as questões se tornam mais intensas, em função da desigualdade social e pobreza que vêm se agravando nas últimas décadas, excluindo grande parte da população. 
Essas metrópoles apresentam escassez de capital, poucos centros urbanos sobrecarregados de mão-de-obra provenientes do campo e inadequadas aos novos modos de produção. A superpopulação ocasionada pela redução agrária provocou uma distribuição espacial urbana com disparidades geográficas e sociais. A fragilidade da atuação do Estado na provisão de serviços urbanos dificulta a atração dos investidores internacionais pela dificuldade em se adotar políticas institucionais que integrem e complementem os mercados onde suas empresas atuam.

Registros históricos demonstram que a formação e a organização da cidade de São Paulo se condicionou pela relação existente entre a industrialização e urbanização, resultantes do próprio processo de modernização. Desde o início da redemocratização política, a cidade de São Paulo se apresenta diante do paradoxo de cidade mundial inserida na economia global, ao mesmo tempo em que as questões excludentes são cada vez maiores. Uma questão foi levantada por Rolnik (2004): "São Paulo estaria deixando de ser a cidade do trabalho, a força propulsora do país?“. Essa inquietação é decorrente dos indícios visíveis, inclusive nas estatísticas oficiais, sobre a transição econômica por que passa a cidade. Ora se traduz por uma percepção do desemprego e o crescimento da informalidade nas relações de trabalho, ora pela imagem de cidade globalizada, visível pelas ilhas de riqueza nas inúmeras centralidades, principalmente no quadrante sudoeste da metrópole. De fato, a redução da participação da indústria metropolitana na força industrial total do estado de São Paulo tem diminuído significativamente ao longo das últimas três décadas, enquanto ocorre um forte aumento do setor terciário, conforme demonstrado no Gráfico 1. 


\section{Gráfico 1}

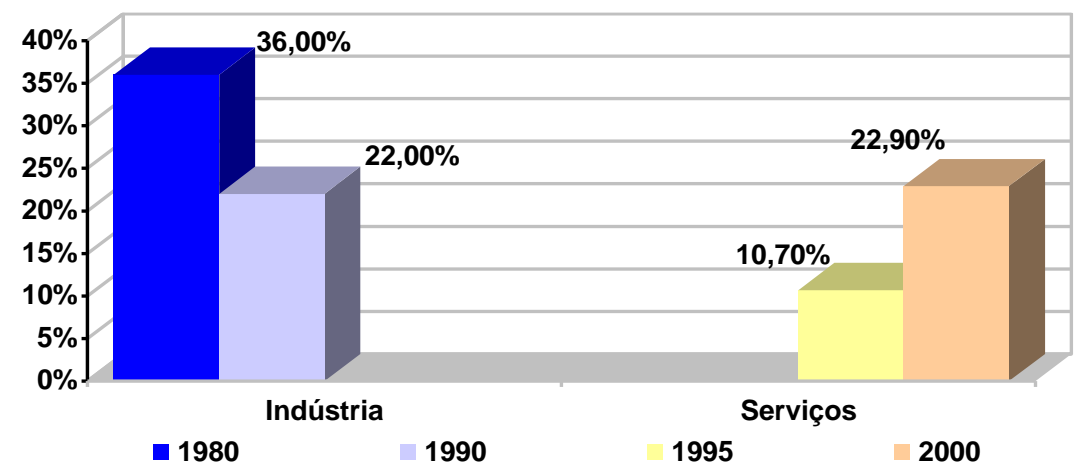

Declínio da indústria e crescimento de serviços em São Paulo.

Fonte: Sistema Estadual de Análise de Dados (SEADE), 2005.

Contudo, essa tendência não apresenta novidades significativas, uma vez que a maioria das metrópoles mundiais tem se encaminhado para os setores terciários. De acordo com Rolnik (2004), levantamentos de indicadores econômicos e sociais demonstram que São Paulo continua centralizando as operações financeiras e grande parte dos empregos bem remunerados do país, possui as maiores empresas de telecomunicações brasileiras e $70 \%$ do seu comércio eletrônico é movimentado pela cidade de São Paulo. Esse modelo de negócio, recém iniciado, confirma a importância estratégica da cidade, não apenas nas atividades econômicas geradas localmente, mas também como o maior pólo de reconversão econômica para o resto do país e confirma as afirmativas de Castells (1999) de que são Paulo é um elo importante no espaço de fluxos da grande rede mundial.

O transporte individual continua sendo a primeira opção da maioria da população de classe média e alta, sacrificando principalmente as áreas centrais com congestionamentos insolúveis e principalmente pela reutilização de espaços centrais para estacionamentos. A cidade de São Paulo encontra-se, atualmente, fragmentada, com ilhas de riqueza, enquanto os bairros periféricos continuam com altas taxas populacionais e um cotidiano restrito ao próprio bairro ou entorno.

No limite, trata-se da dissolução da São Paulo de fronteiras abertas, que dava a possibilidade concreta do desenvolvimento humano individual e coletivo por meio da intensidade de trocas $e$ interações. As fronteiras internas assumiram a materialidade física dos muros, grades e guaritas, sitiando a cidade e confinando os 
cidadãos a uma vida apenas entre familiares e iguais (ROLNIK, 2004, p. 175).

Desse modo, pode-se concluir que essas novas formas urbanas caracterizam-se, essencialmente, pelas tendências contraditórias das organizações contemporâneas e apresentam características que não se encaixam em nenhum quadro de referência já consolidado. São Paulo apresenta as contradições das formas urbanas que se constituem no novo milênio - as megacidades - como descreve Castells (1999); os paradoxos das megaorganizações, identificadas por Fischer (1996); dispersão e fragmentação, características da cidade contemporânea na perspectiva do cenário global, como escrevem Meyer; Grostein; Biderman (2004); mas também pela agregação e articulação no desenvolvimento econômico sustentável em suas inúmeras centralidades, características das cidades modernas. Concentra pólos de desenvolvimento de produção altamente qualificados, como aponta Rolnik (2004), ao mesmo tempo em que absorve segmentos excluídos da população, provenientes das mais variadas regiões, nacionais e estrangeiras, que chegam em busca de oportunidades de emprego e renda. Convivem, lado a lado, tanto as elites gerenciais formais, quanto as lideranças representantes das redes virtuais e do comércio informal, ambas a serviço do grande capitalismo global. As desigualdades sociais se acentuam cada vez mais, potencializando os problemas crônicos da exclusão social, ao mesmo tempo em que prosperam gerando riquezas e atraindo cada vez mais as populações em busca de emprego e renda. Os desafios em se encontrar novas formas de gestão de cidades por meio de experiências a serem compartilhadas por setores públicos e privados dependem, portanto, cada vez mais, do grau de harmonização entre recursos econômicos, processos políticos, sistemas e funcionalidades dos programas públicos e privados, tomadas de decisão, articulações entre os atores, cultura, atitude pessoal e outros, que se traduzem em valores e crenças compartilhados das populações. 


\section{Experiências Participativas na Gestão do Centro Histórico}

O surgimento dos movimentos participativos na cidade de São Paulo coincide com o intenso movimento de criação de organizações não-governamentais (ONGs), ao longo dos anos 1990, em quase todas as partes do mundo. No Brasil, tem o seu marco formal na Constituição de 1988, que consagrou o princípio de participação da sociedade civil. Esse princípio é explicado por Dagnino (2004) como a consolidação de duas tendências importantes: a primeira se relaciona a uma aposta na possibilidade da ação conjunta, para o aprofundamento democrático, em que a gestão do Estado pudesse ser compartilhada com a sociedade e a segunda é a emergência de um projeto de Estado mínimo que se isenta progressivamente de seu papel de garantidor de direitos, pelo encolhimento de suas responsabilidades sociais e sua transferência para a sociedade civil. Este projeto constitui o núcleo do processo global de adequação das sociedades ao modelo neoliberal produzido pelo Consenso de Washington ${ }^{7}$. Desse modo, a virada do milênio se caracteriza por um deslocamento de papéis entre governos, empresas e sociedade civil, incorporado no ideário das transformações sociais no mundo inteiro. As experiências participativas na gestão das cidades incluem, como principais atributos de sucesso, a integração efetiva entre as esferas públicas e sociedade civil em projetos estratégicos que resultem em desenvolvimento sustentável do ponto de vista econômico, político, cultural e social das cidades.

Wilheim (2004) aponta para as inúmeras possibilidades que a cidade de São Paulo apresenta nesta virada de século XXI, para a revisão de seu modelo urbano, pela aprovação do Plano Diretor Estratégico (PDE), elaborado com a efetiva participação da sociedade, a implantação das subprefeituras e respectivos conselhos de representantes e da obrigatória elaboração dos planos regionais. Vale ressaltar, entretanto, que as 3 mil pessoas e 521 entidades, que participaram da elaboração do PDE, representam uma minoria insignificante, se comparada à população total paulistana, de 11 milhões de habitantes, no ano de $2004^{8}$. Pode-se afirmar, portanto, que a participação nos processos de gestão da cidade se restringe aos poderes locais, a uma modesta amostra dos formadores de opinião e

\footnotetext{
${ }^{7}$ O Consenso de Washington foi o resultado de uma reunião realizada, no International Institute for Economy (1989), quando funcionários do governo dos EUA, dos organismos internacionais e economistas latino-americanos discutiram um conjunto de reformas essenciais para que a América Latina superasse a crise econômica e retomasse o caminho do crescimento. As conclusões desse encontro passaram a ser denominadas informalmente como o Consenso de Washington, expressão atribuída ao economista inglês John Williamson.

${ }^{8}$ Censo do ano 2000. Fundação Sistema de Análise de Dados (SEADE), 2005.
} 
pequenos grupos que sempre estiveram presentes na vida política e na constituição de São Paulo.

A sociedade paulistana, de modo geral, pode ser associada a um padrão bastante distinto dessa pequena minoria: "Vambora, vambora! Tá na hora, vambora, vambora"9. O refrão repetido diariamente pela rádio paulistana e outros símbolos - aqui se trabalha, a cidade que não pode parar, o paulistano é sério e não sabe se divertir, o paulistano está sempre com pressa - testemunham o padrão que se desenvolveu no imaginário coletivo sobre a experiência de se viver em São Paulo. A cidade que acolhe para o trabalho exclui a possibilidade do bem-viver e, com isso, o afeto e a estima pela cidade não são valores que tenham se desenvolvido na população paulistana. A manutenção do emprego, quase sempre obtido com dificuldades, leva as pessoas a conviver com os desafios cotidianos impostos pela metrópole, fria e impessoal, e buscar o refúgio acolhedor do campo ou praia nos finais de semana. A sensação do paulistano de pertencimento ao lugar não se vincula com a cidade em si, mas ao pequeno entorno de seu cotidiano, em geral a rua ou o bairro em que ele vive. Nesse sentido, no que se refere ao sentimento do paulistano sobre a cidade, é importante ressaltar que a cidadania assume graus diferenciados para o seu exercício, dependendo do bairro ou da rua onde se vive, pois, "não é absurdo afirmar que somos mais ou menos cidadãos de acordo com o espaço em que estejamos inseridos" (OLIVEIRA, 1999).

As análises desse estudo se baseiam nos projetos estratégicos promovidos no Centro Histórico de São Paulo, inicialmente articulados pela Associação Viva o Centro e que foram sendo remodelados com a entrada de novos atores, em função dos seus desdobramentos e resultados. As principais percepções sobre as experiências participativas para a gestão do Centro Histórico de São Paulo são analisadas a partir do quadro de referência de Cidades Estratégicas, proposto por Borja (1996), estruturadas nas dimensões econômica, social e política. Os principais desafios a serem enfrentados concluem as análises.

\footnotetext{
${ }^{9}$ Refrão repetido diariamente pela rádio Jovem Pan, especialmente nos horários em que o paulistano se locomove no trânsito nos sentidos trabalho-casa-trabalho, marcados por congestionamentos crônicos.
} 


\section{Dimensão Econômica}

No que se refere à capacidade de reativação produtiva dos locais recuperados, pode-se afirmar que, embora o projeto São Paulo Centro: Uma Nova Abordagem seja um detalhado estudo urbanístico sobre a região central da cidade de São Paulo, com sugestões de intervenções em áreas estratégicas, não apresenta análises de viabilidade econômicofinanceira e estimativa de retorno para empreendedores que decidam investir nas regiões em que foram propostas ações estratégicas. Ao contrário do que ocorreu no início do século XX, na gestão Antonio Prado (1899-1910), o Centro Histórico de São Paulo, atualmente, não apresenta, aos investidores, motivações diferenciadas das inúmeras centralidades disponíveis em São Paulo e em cidades adjacentes, que competem entre si na atração de novos empreendimentos. Os elementos que levam os investidores a optar por essa ou aquela localidade variam enormemente em função do tipo de atividade a ser desenvolvida, porém, os resultados financeiros são decisivos quando existe equivalência nos outros quesitos. Subsídios tributários ou facilidades para os investidores adquirirem terrenos ou edifícios seriam algumas promoções possíveis aos governos locais, porém, a autonomia das cidades para prover subsídios tributários é mínima, pois os principais tributos são reservados à União e aos Estados ${ }^{10}$.

Entretanto, a reativação das bases produtivas do Centro Histórico não parece ser a questão central da região. Atualmente a região oferece mais de 1 milhão de empregos num perímetro de $17 \mathrm{~km} 2$, o que significa quase 60 mil empregos por km2 (MEYER, 2000). Possivelmente, esses empregos estejam inadequados ao perfil de cidade cultural e terciarizada, e, portanto, incompatíveis com as expectativas dos projetos que vêm sendo conduzidos, que pretendem maximizar a utilização dos recursos existentes em atividades culturais.

A origem dos recursos financeiros para a construção do Complexo Cultural Júlio Prestes e da Estação da Luz foram provenientes do governo estadual. No primeiro, $\mathrm{R} \$ 44$ milhões na gestão Mário Covas e no segundo, R\$ 36 milhões na gestão Geraldo Alckmin (VIVA O CENTRO, 2005). Em função das atividades culturais do complexo, principalmente da Orquestra Sinfônica do Estado de São Paulo (OSESP), que atrai um público de classe

\footnotetext{
${ }^{10}$ Impostos federais: PIS, COFINS, IRLL, IPI, CSLL, CPMF. Impostos estaduais: ICMS. Impostos municipais: ISS, IRRF e ITBI.
} 
média e alta para a região, existe um esforço para a preservação e manutenção dos edifícios recuperados, por meio de um policiamento intensivo na localidade, pela ausência de outras atividades no entorno, a despeito do empenho que o governo municipal vem dedicando na criação de projetos que se integrem com as novas funcionalidades da área. É o caso da proposta de reativação da área degradada, que ficou conhecida como cracolândia, por abrigar um contingente da população excluída ao longo das últimas décadas. O Programa de Incentivos Seletivos, da Prefeitura Municipal de São Paulo, estabelece um mínimo de R \$ 50 mil e os investidores terão como incentivos fiscais descontos de até $60 \%$ no Imposto sobre Serviços (ISS) e 50 \% nos Imposto Predial e Territorial Urbano (IPTU) e Imposto de Transmissão "Inter Vivos" (ITBI), os únicos impostos reservados à cidade, pois, como já se observou anteriormente, esses incentivos são modestos se comparados aos tributos reservados à União e aos Estados. Pode-se concluir, então, que sem uma articulação com outras instâncias públicas, não se cria qualquer diferenciação para os possíveis investidores de outras centralidades da cidade.

A desapropriação e intervenção urbanística proposta para a área destinada ao Pólo Luz teve início em setembro de 2005 e confirmam o pensamento de Sanchez (2003) sobre os imperativos da reestruturação do espaço que não tratam as questões sociais como prioritárias.

Entende-se, nesse caso, que a população esteja inadequada para as novas finalidades da área a ser recuperada e sua transferência para outras regiões da cidade se tornou necessária. Essa desestabilização das organizações não se configura como uma novidade, porém, parece que se tornam mais freqüentes e mais injustas, no sentido que Drucker (1993) adota para expressar a desestabilização social temporária que ocorre nas organizações contemporâneas, caracterizadas pelas rápidas transformações. No entanto, essa constatação tem a finalidade de exercer apenas uma vigilância crítica no sentido de se criar instrumentos sociais que previnam os abusos contra determinados segmentos sociais, pois, como já se discutiu anteriormente, as novas formas urbanas que se configuram na atualidade, ainda se apresentam sem respostas definitivas.

Uma intervenção proposta no projeto São Paulo Centro: Uma Nova Abordagem foi a criação de um centro comercial especializado no Pátio do Pari, que atrairia um sem número 
de outras atividades voltadas ao desenvolvimento local e conseqüente geração de emprego e renda. O complexo deveria integrar programas habitacionais, criação de escolas para a capacitação profissional e infraestrutura familiar adequados ao perfil dos novos moradores da localidade, com financiamentos adequados à renda da população potencial para essa área. Identifica-se, nessa proposição, a necessidade da constituição de alianças estratégicas entre empreendedores, poderes públicos, empresários de diversos setores, universidades e outros.

As dificuldades que se apresentam, contudo, são os dilemas que se configuram nas alianças estratégicas necessárias ${ }^{11}$. Numa tentativa de estender esse conceito às experiências entre empresas, poderes públicos e sociedade civil, os interesses podem ser de outra natureza e não apenas resultados financeiros. Contudo, a confiança entre os parceiros parece ser $o$ principal ativo estratégico dessas alianças, pois, de acordo com Hitt (2004), comportamentos oportunistas vêm à tona quando uma aliança é fundamentada na percepção de uma confiabilidade que não existe. Segundo Hitt (2004), as ações governamentais em países emergentes têm se mostrado um dos importantes inibidores dessas alianças, pois o nível de confiança pode ser afetado pela possibilidade, que esses poderes possuem, de modificar as regras do jogo através de decretos que coloquem em risco os acordos iniciais.

Além das questões já mencionadas, a política habitacional brasileira se apresenta como uma das principais questões envolvidas na reativação das bases econômicas do Centro Histórico de São Paulo. Os edifícios degradados, existentes nessa área, necessitam de projetos de reordenamentos habitacionais em função do perfil sócio-econômico-cultural dos novos moradores. O perfil dos novos moradores está vinculado, por sua vez, às características das empresas que irão se desenvolver nas localidades. Um imperativo fundamental para o desenvolvimento de projetos de reordenamentos habitacionais é a flexibilização dos modelos de financiamentos para aquisição de terrenos e moradias. A despeito dos programas habitacionais subsidiados pelos governos, por seus objetivos de cunho social e limitados à população que vive em condições de risco ${ }^{12}$, os programas habitacionais

\footnotetext{
${ }^{11}$ São alianças postas em prática por um grupo de empresas inter-relacionadas e comparáveis, a fim de servir aos interesses comuns de todos os sócios. Quando as alianças ocorrem entre organizações privadas, os resultados financeiros se constituem na principal motivação das alianças estratégicas. A sustentação dessas alianças é mais ou menos efetiva se os resultados comuns são melhores que os resultados individuais de cada parceiro (HITT, 2004).

${ }^{12}$ Programas Habitacionais da Secretaria da Habitação e Desenvolvimento Urbano (SEHAB) ou da Companhia de Desenvolvimento Habitacional Urbano (CDHU).
} 
brasileiros adotam os modelos instituídos pelo Sistema Financeiro da Habitação (SFH), desde o início do regime militar (Lei 4.380/1964) e, a despeito das emendas que modificam apenas os detalhes sobre a alocação dos recursos, mantém as características tecnocratas e centralizadoras, inadequadas para o quadro mutável da sociedade atual.

As principais percepções sobre a dimensão econômica sugerem a falta de uma liderança capaz de conduzir e articular as alianças estratégicas necessárias para se concretizar as ações propostas. Como lembra Borja (1996), o resultado do plano estratégico não é mais uma norma ou um programa de governo, como ocorria nos planejamentos de cidades até o final do século XX. Trata-se de um contrato político entre as instituições públicas e a sociedade civil que definem como será a cidade que querem no futuro. Por isso, o processo posterior à aprovação do plano, sua continuidade e a implementação dos projetos e programas estratégicos são tão ou mais importantes que o processo de elaboração e aprovação consensuais. Os projetos estratégicos que desenvolvem e implementam as ações devem ser flexíveis e articulados em alianças estratégicas que possibilitem a captação de recursos, transferências de tecnologia e cooperação técnica.

\section{Dimensão Social}

No que se refere à integração efetiva entre as esferas públicas e a sociedade que contribuam para que a população adquira empowerment, se faz necessária uma definição do conceito de cidadania proposto para este estudo. Entende-se por cidadania, no contexto de experiências participativas para a renovação e gestão do Centro Histórico de São Paulo, como a atitude que leva o indivíduo a se afirmar na sociedade pela aquisição de direitos e, com isso, ampliar sua capacidade de proposição e execução de ações intersetoriais que se traduzem em melhorias da qualidade de vida, individual e coletiva dos moradores e usuários, e da qualidade ambiental.

Nesse sentido, pode-se afirmar que o programa de Ações Locais ocorreu a partir da percepção de que a cidadania poderia ser exercida no âmbito da rua onde se vive, numa postura ativa de negociação com o poder público para obtenção de melhorias e solução dos problemas. E foi uma experiência bem sucedida no que se refere à mobilização da sociedade local, dentro de uma modelagem organizacional no setor público, como define Cavalcanti (2005). A despeito da modelagem organizacional ainda não apresentar um 
quadro teórico totalmente consolidado, é válido analisar a experiência do programa de Ações Locais dentro da percepção que é possível se estabelecer uma sólida ponte entre a teoria das organizações e a prática da mudança organizacional. As lideranças participam ativamente nos modos de organizar, a fim de se alcançar resultados sofisticados e sincronizados com o mundo empresarial em rápida evolução. Essas novas experiências são decorrentes da administração pública gerencial, cujo objetivo é superar as dificuldades e inconsistências da administração burocrática, mantendo, contudo, alguns de seus aspectos, em especial no núcleo estratégico. O espaço de atuação do programa de Ações Locais situase nas atividades transferidas à sociedade mediante o processo de publicização, ou seja, a adoção pela sociedade de formas de produção não-lucrativas de bens e serviços públicos ${ }^{13}$. Trata-se, portanto, de um modelo de gestão compartilhada no âmbito local com um formato simples, conforme depoimento do presidente da diretoria executiva da Viva o Centro, Marco Antonio Ramos de Almeida (2005):

As Ações Locais partem do particular para o todo, já que é mais fácil uma pessoa cuidar da sua porta do que do bairro inteiro (...) O processo de mobilização social tem se multiplicado rapidamente ao longo dos dez anos do programa: o projeto piloto tinha como objetivo testar a idéia. De lá para cá, não parou de se expandir. E o número deverá aumentar, pois, já há uma movimentação para a abertura das Ações Locais nas regiões da Santa Ifigênia e do Glicério. $^{14}$

As ações de recuperação arquitetônica e urbanística dos edifícios, praças e ruas para embelezar a cidade requerem ações da população moradora ou usuária a fim de revitalizar o espaço recuperado, ou seja, a vida que volta à localidade deve permanecer. Zelar pela rua em que se mora ou se trabalha a fim de buscar melhorias de qualidade de vida urbana é também o pensamento de Jaime Lerner, que define as ações locais, rápidas e econômicas, independentes dos planos das cidades como acupuntura urbana:

\footnotetext{
${ }^{13} \mathrm{O}$ processo ocorre através da transformação de instituições públicas prestadoras de serviços em entidades de direito privado sem fins lucrativos, com o acompanhamento do governo, através de contrato de gestão estabelecido entre as partes, e da sociedade civil, por intermédio de conselhos administrativos. Esse projeto denomina-se Organizações Sociais (OS) ${ }^{13}$. O preceito básico das OS é possibilitar uma administração mais flexível e ágil para as instituições, sem, contudo perder a capacidade de controle, uma vez que atuam em áreas essenciais para a população (CAVALCANTI, 2005, p.77).

${ }^{14}$ Dez Anos de Ações Locais. Revista URBS. São Paulo, Ano IX, No 38, agosto / setembro 2005.
} 
Tais ações locais atuam como uma centelha que se espalha num processo de mudança de atitude da população, cujos efeitos se incorporam no cotidiano e as pessoas passam a admirar $e$ respeitar sua cidade. Não existe um lugar feio na cidade que não possa ser embelezado (...) As escolas também devem incentivar o amor pelas cidades desde cedo, pois, cada criança que sabe desenhar sua cidade vai respeitá-la muito mais (informação verbal) ${ }^{15}$.

Contudo, a questão que se configura no Centro Histórico da cidade de São Paulo, em especial nos três locais observados diretamente - Vale do Anhangabaú, Praça Ramos de Azevedo e Praça da Sé - são suas funções prioritárias como espaços de conexão ao transporte coletivo da população paulistana em geral. O que se observou é que o sistema de transportes coletivos, provenientes de todas as regiões da metrópole, obriga os passageiros a caminharem a pé por esses locais em suas interligações ônibus-metrô-ônibus no trajeto para o trabalho. O resultado é que essa imensa população, que apenas utiliza esses espaços para atingir seu objetivo diário, não desenvolve uma relação afetiva com esses locais, para passeios, lazer ou diversão. Diante do potencial econômico-financeiro dessa massa trabalhadora que circula diariamente pelo Centro Histórico de São Paulo, estimada em 2 milhões de pessoas (MEYER, 2000), novas funções são criadas para esses espaços: o comércio informal e a mendicância.

A economia informal gerada pelos camelôs é questão relevante que desafia o sucesso dos projetos do Centro Histórico de São Paulo, de acordo com a opinião dos promotores das ações. Segundo observações efetuadas, os camelôs ocupam as calçadas de todos os pontos que funcionam como interligação do transporte coletivo e em quase todas as ruas. $\mathrm{O}$ pensamento generalizado sobre o comércio dos camelôs é que essa prática esconde aspectos nem sempre evidentes, mas certamente graves, como a questão da criminalidade que não se dá na aparência dos fatos do cotidiano. O deslocamento do poder nas sociedades contemporâneas é uma tendência que tende a se acentuar, por conta das redes virtuais que se organizam independentemente das regulamentações formais dos sistemas políticos,

\footnotetext{
${ }^{15}$ Entrevista de Jaime Lerner, no lançamento do livro Acupuntura Urbana, em São Paulo, 13/10/2005.
} 
como afirmam Castells (1999), Meyer; Grostein; Biderman (2004) e Fischer (1996). Enfrentar o conflito de forma efetiva envolve repensar, inclusive, os sistemas tributários brasileiros, a fim de se criar incentivos reais para que a população informal se inclua nos sistemas formais, naturalmente.

Embora seja inegável o avanço nos processos democráticos no Brasil ao longo da última década, existe uma barreira difícil de transpor a fim de se alcançar o patamar mínimo da cidadania idealizada pelos direitos republicanos, que expressam o conceito de cidadania na sua mais ampla concepção, pois, como reconhece Bresser Pereira (1997), sequer os Direitos Humanos $^{16}$ foram totalmente assegurados no Brasil. Os movimentos participativos intensificados pelas ONGs têm contribuído, de fato, para minimizar problemas crônicos relacionados à exclusão social, porém, Dagnino (2004) apresenta uma opinião relevante sobre essas experiências participativas em que a sociedade civil assume as responsabilidades do Estado e questiona se seria papel das ONGs assumir as funções das práticas sociais em vez de promover a discussão dos projetos políticos com os poderes públicos:

$O$ processo de encolhimento do Estado e da progressiva transferência de suas responsabilidades sociais para a sociedade civil, que tem caracterizado os últimos anos, estaria conferindo uma dimensão perversa a essas jovens experiências (...). [as ONGs] percebem essa confluência perversa como um dilema que questiona o seu próprio papel político: "o que estamos fazendo aqui?", “que projeto estamos fortalecendo?”, “não ganharíamos mais com outro tipo de estratégia que priorizasse a organização $e$ a mobilização da sociedade, ao invés de atuar junto com o Estado?" (DAGNINO, 2004, p.98).

O que está sendo proposto por Dagnino (2004), pode ser interpretado como o deslocamento da sociedade civil no sentido de exigir que o Estado e o Mercado cumpram seus papéis, em vez de trabalhar para o Estado, executando funções de sua responsabilidade. Como lembra Bresser Pereira (1997), viver em sociedade implica na resolução dos problemas da ação coletiva, cuja responsabilidade fica a cargo da

\footnotetext{
${ }^{16}$ Os Direitos Civis, Políticos e Sociais foram unidos na denominação Direitos Humanos, em 1948.
} 
institucionalização do Estado e o desenvolvimento econômico fica a cargo da institucionalização do Mercado, que pressupõe o trabalho em conjunto a fim de competir pelo produto social.

\section{Dimensão Política}

Com relação à existência ou criação de incentivos dos poderes públicos que complementem as dimensões anteriores, pode-se afirmar que as administrações municipais que geriram a cidade até o ano 2001, cujos prefeitos foram eleitos por voto popular após o longo período do Regime Militar (1964-1985) não se ocuparam em promover ações na área central da cidade de São Paulo ${ }^{17}$. Desse modo, a vocação empresarial da Associação Viva o Centro se traduziu em ocupar um espaço político menosprezado pelas esferas públicas municipais ao longo de algumas décadas, no processo de reversão da degradação do Centro Histórico da cidade. Essa iniciativa pode ser entendida de duas maneiras. A primeira é o interesse empresarial resultante da análise dos custos $\mathrm{x}$ benefícios entre promover ações de melhorias nos espaços públicos, no sentido de se preservar as empresas localizadas no Centro Histórico, ou mudar as empresas para as centralidades na região sudoeste da cidade, que apresentam uma maior compatibilidade com seus estilos corporativos. A segunda pode ser associada a um questionamento ao governo local, como lembra Borja (1996), pois, questionar o governo local, suas competências e sua organização é o início de uma reforma política radical, sem a qual não se constrói os novos modelos de gestão estratégicos, no sentido de mobilizar os poderes públicos, empresas e sociedade em ações e parcerias eficazes.

As análises efetuadas levam à conclusão que a Associação Viva o Centro vem atuando nas articulações dos projetos de renovação do Centro Histórico de São Paulo motivada pela possibilidade de conciliação entre a práticas de gestão empresarial e a finalidade maior do interesse público, tendo em vista os desdobramentos e resultados que se seguiram, levando o poder público municipal a assumir efetivamente os processos de renovação do Centro Histórico de São Paulo, com a criação do programa Ação Centro, em 2003.

\footnotetext{
${ }^{17}$ O primeiro prefeito eleito, Jânio Quadros (1986-1988), priorizou as grandes obras de infra-estrutura, especialmente na região sudoeste da cidade de São Paulo. A conclusão dessas obras ocorreu apenas na gestão de Paulo Maluf (1993-1996), pois a gestão Luiza Erundina (1989-1992), antecessora de Maluf, apresentava orientação política diferente e paralisou as obras. A eleição de Celso Pitta (1997-2000) resultou na retomada das grandes obras viárias, com o início da construção do fura-fila, idealizado na campanha de 1996, e que ainda se encontra em adamento, na atual gestão Serra (2005).
} 


\section{Desafios para a Gestão do Centro Histórico de São Paulo}

No que se refere aos desafios que devem ser enfrentados, dentro do conceito de Cidades Estratégicas, uma das grandes questões, que podem resultar em conflitos irreconciliáveis, são as grandes redes de poder das elites econômicas informais, como o comércio informal e narcotráfico, originados principalmente fora das fronteiras nacionais e que encontram seus pontos de apoio nas megacidades. A questão dos camelôs é um dos grandes desafios aos projetos, porém, como afirmam Castells (1999), Meyer; Grostein; Biderman (2004) e Fischer (1996), o deslocamento do poder nas sociedades contemporâneas é uma tendência que tende a se acentuar, por conta das redes virtuais que se organizam independentemente das regulamentações formais dos sistemas políticos.

Outro desafio, apontado por Borja (1996), que deve ser enfrentado, é a qualidade de vida. Existem, contudo, grandes obstáculos para se alcançar uma conceituação precisa do que vem a ser qualidade de vida, como lembra Forattini (1991). As percepções individuais, que acentuam seu caráter subjetivo, não podem ser desconsideradas nas possibilidades de mensuração, pois constitui parte que lhe é inerente. De modo geral, reconhecem-se dois tipos de necessidades específicas - as concretas, de caráter geral como alimentação e a moradia, e as abstratas, que se revestem de aspecto mais particular, como a auto-estima. Dessa maneira, partindo-se da premissa de que é a opinião do indivíduo que identifica a ação de fatores determinantes da qualidade de sua vida, buscou-se identificar como ela é percebida, no Centro Histórico de São Paulo, por seus moradores, servidores públicos e empresários que lá trabalham. A população avalia sua qualidade de vida como boa ou adequada. O Centro Histórico de São Paulo possui, ainda, um espaço privilegiado de cultura, história e desenvolvimento urbano que lhe confere atributos e qualidades especiais que o distinguem das demais regiões da cidade. O paulistano, morador do Centro Histórico de São Paulo, demonstra o sentimento de pertencimento ao local, visível pelos depoimentos coletados, que transmitem a idéia que o Centro possui todas as qualidades de um bairro, onde se passeia no fim de semana com o cachorro pelas calçadas largas, com serviços de todo o tipo à disposição. E também toda a agitação do coração de uma cidade grande e pulsante, de uma das maiores metrópoles do mundo. Para alguns moradores, o encantamento está na vista que têm de suas janelas, que pode ser um prédio construído na primeira metade do século passado, uma praça cheia de árvores ou simplesmente as luzes 
da cidade vistas de cima. A possibilidade de encontrar nas redondezas tudo o que procura do pão quentinho ao comércio especializado.

A governabilidade parece ser, contudo, o grande desafio para a gestão do Centro Histórico de São Paulo, devido à dificuldade natural da gestão de um espaço para onde converge quase todo o sistema viário metropolitano. Enquanto a população residente é de 500 mil habitantes, a população usuária circulante em função das interligações do sistema de transportes é de 2 milhões de pessoas por dia. A descentralização da gestão pública, por meio da criação das 31 subprefeituras, em 2002, poderá facilitar a solução dos problemas locais, desde que essas subprefeituras atuem muito próximas aos objetivos estratégicos da metrópole como um todo e bem articuladas com a sociedade local. Por outro lado, as questões metropolitanas poderão se tornar mais complexas, pois, enquanto o tema da gestão das áreas metropolitanas vem assumindo um papel estratégico na agenda das políticas públicas, verifica-se, por outro lado, que os arcabouços institucionais não vêm proporcionando soluções satisfatórias. A organização e a gestão das áreas metropolitanas brasileiras se encontram, atualmente, em um vácuo institucional deixado pela Constituição Federal de 1988 e também não ocupado pelas respectivas constituições estaduais (KLINK; SANTOS, 2004).

Essa questão é apontada por Campos Filho (2003) como muito grave e ainda não resolvida no Plano Diretor Estratégico (PDE) para a cidade de São Paulo, aprovado em 2002. Os principais problemas urbanos apontados são o congestionamento crescente, as enchentes e a população sem moradia - favelados, moradores de rua e invasores de mananciais. Essas questões vêm sendo discutidas, ao longo das últimas décadas, por urbanistas e demais setores especializados e, a despeito de possuírem propostas de soluções técnicas, não se viabilizam pela falta de articulação entre os poderes públicos nas três esferas: federal, estadual e municipal ${ }^{18}$. Por outro lado, a Constituição Federal, em seu artigo 182, estabeleceu que a única lei municipal obrigatória a ser seguida pelos níveis de governo estadual e federal é a do Plano Diretor Municipal, como condição para a cidade cumprir sua função social (CAMPOS FILHO, 2003). A questão é que se cada nível de governo

\footnotetext{
${ }^{18}$ No caso dos congestionamentos, a solução depende do metrô que se encontra nas mãos do Governo Estadual, por ser a instituição que apresenta capacidade financeira e administrativa para conduzir o projeto; as enchentes dependem da construção de piscinões, com obras a serem implantadas com dinheiro estadual em terreno municipal; favelados, moradores de rua e invasores de mananciais necessitam de subsídio para construir suas moradias, cujos recursos se encontram nas mãos do governo estadual - Companhia de Desenvolvimento Habitacional e Urbano (CDHU).
} 
desenvolver propostas divergentes ou mesmo conflitantes entre si, as soluções deixam de ser soluções e podem agravar os problemas que se quer resolver. Com isso, conclui-se que existe a necessidade de um vínculo garantidor que as condições técnicas estejam coordenadas entre si e que, atualmente, não parecem estar presentes na interpretação que se dá ao que está contido no Plano Diretor Municipal.

\section{Conclusão}

Os projetos desenvolvidos no Centro Histórico de São Paulo apresentam uma consciência e uma intenção convergentes às dimensões que devem ser levadas em conta nas Cidades Estratégicas, assinaladas por Borja (1996) e perseguem os objetivos que deveriam minimizar os problemas e desafios a serem enfrentados. No entanto, quando esses projetos são colocados em prática, as dificuldades de articulação e integração entre os atores têm se mostrado quase intransponíveis, pelas questões de governança que ainda não apresentam progressos significativos. As experiências participativas de renovação do Centro Histórico de São Paulo parecem carecer de uma liderança capaz de unir empreendedores efetivamente convencidos que se trata de uma região que se fortalecerá ao longo dos anos, independentemente das mudanças de orientação política dos poderes municipais, o que poderá demandar um tempo significativo ou nunca se efetivar, pois, ao longo da história da formação da cidade de São Paulo o que ficou evidente é que os interesses partidários, pessoais e dos grupos da elite paulistana se sobrepujam aos interesses coletivos.

As experiências participativas para a renovação e a gestão do Centro Histórico da cidade de São Paulo são fundamentais, necessárias e caminham no sentido de se revalorizar um espaço riquíssimo em possibilidades de diversas naturezas, porém, irrelevantes para garantir um posicionamento competitivo da cidade de São Paulo na economia globalizada, pois São Paulo já se encontra nessa posição, a despeito dos contrastes já mencionados. Ao longo do século XX a cidade conviveu e ainda convive com suas contradições: o surgimento de diversas centralidades auto-sustentáveis isoladas umas das outras enquanto centros de poder e de decisão, mas integradas nas suas problemáticas, principalmente nas suas demandas sociais. Cada uma com autonomia e características sócio-econômicas culturais próprias, porém, com uma estrutura funcional que se inter-relaciona, de forma imbricada, principalmente em relação aos sistemas de transportes e demandas sociais, 
intensificando as complexidades na gestão municipal para as diversas realidades paulistanas.

Sobre as parcerias entre poderes públicos e sociedade civil na gestão compartilhada do Centro Histórico de São Paulo serem sustentáveis ao longo do tempo, ainda não é possível afirmar se esses processos apresentam efetividade ou não, pois, não se pode afirmar que as parcerias foram resultantes da consistência dos arranjos institucionais ou das lideranças pessoais dos atores envolvidos. O resultado final da acomodação das pessoas nas organizações constitui-se na configuração do campo, temporariamente, pois é natural que essa dinâmica se modifique de acordo com a alteração dos recursos de poder dos atores e com a mudança relativa na posição dos mesmos, com a entrada e saída de outros. Os elementos não-racionais presentes nas organizações - liderança, poder, cultura e orientação política - que se traduzem em valores e crenças, nível de confiança entre os parceiros e outros, interferem de modo relevante na condução das ações coletivas.

A questão do desenvolvimento de pólos culturais no Centro Histórico esbarra em dificuldades naturalmente complexas. O Centro Histórico se consolidou, ao longo dos últimos trinta anos, como centro de absorção da população excluída e degradação ambiental, formando-se uma muralha imaginária que isola essa região das centralidades que concentram o poder econômico e financeiro da metrópole. O esforço para se reverter a centralidade enquanto espaço de cultura, diversão e lazer tem sido enorme, com policiamento intensivo, inúmeras ONGs atuando em conjunto com a sociedade civil, empresas e governos. Porém, são necessárias iniciativas integradas para geração de emprego e renda compatíveis às novas funções da região, a fim de que os mecanismos de preservação ocorram naturalmente. Vale lembrar que experiências em outras cidades mundiais resultaram em insucessos quando não acompanhados de ações articuladas e integradas em torno de um mesmo objetivo.

Além das questões racionais envolvidas, existe a questão cultural incorporada no imaginário coletivo do paulistano, que São Paulo não é uma cidade onde se diverte ou um local de bem-viver. Pesquisas recentes estão interessadas em avaliar se está ocorrendo uma mudança de atitude do paulistano com relação ao lazer na cidade. O estilo do poder público municipal se modificou com relação a esse aspecto ao longo dos primeiros anos da década 
de 2000, demonstrando uma preocupação prioritariamente humanística em suas ações, incentivando atividades culturais inéditas até então, em praticamente todas as regiões da cidade. Contudo, resultados parciais e preliminares de pesquisas revelam que $98 \%$ dos paulistanos se divertem em São Paulo assistindo a televisão em casa com a família.

No âmbito social, o exercício da cidadania no Centro Histórico de São Paulo vem se afirmando por meio das parcerias entre empresas, poderes públicos e sociedade civil na gestão compartilhada para a solução dos problemas cotidianos e com a participação e discussão das questões locais. Os avanços nos processos participativos para a gestão das localidades são visíveis, dado o grau de comprometimento dos atores privados para a manutenção e preservação dos espaços públicos. No momento em que as Ações Locais iniciaram suas atuações, os principais conflitos se tornaram explícitos e tentativas de solucioná-los continuam mobilizando setores empresariais e da sociedade civil. Entretanto, as soluções ainda se apresentam frágeis e se constituem basicamente de paliativos, tanto as ações assistencialistas aos moradores de rua, quanto o policiamento intensivo contra o comércio informal, que se alimenta das grandes redes que abastecem os comércios locais. Essa dinâmica não se modificará enquanto prevalecer o atual sistema de transportes, que concentra os pontos de conexão do sistema viário no Centro Histórico de São Paulo, pelo enorme contingente de pessoas que se deslocam por lá, unicamente como trajeto obrigatório da casa para o trabalho. Essa população não se identifica com o Centro Histórico enquanto espaço de lazer, cultura e diversão e não desenvolverá o sentimento de admiração e de pertencimento à localidade, e, portanto, não desenvolverá vínculos afetivos, necessários para a preservação natural dos espaços públicos.

A percepção da sociedade de que o modelo dualista - governos e empresas - é insuficiente para solucionar os problemas contemporâneos levou ao crescimento dos movimentos participativos com a inclusão da sociedade civil na tentativa de solucioná-los. O propósito das organizações, que até o final dos anos 1980 também podia ser sistematizado dentro desse modelo dualista, ou seja, benefícios individuais decorrem de organizações econômicas e benefícios coletivos decorrem de organizações públicas, também se tornaram simplistas demais para as complexidades das sociedades contemporâneas. Os espaços públicos e privados, que eram sistematizados sob essa mesma lógica, ganharam um componente inédito, ou seja, o espaço virtual. 
A gradativa apropriação do espaço público para finalidades privadas ou a absorção dos espaços privados para finalidades públicas não são processos contemporâneos e muito já se discutiu a respeito. A intensificação dessas práticas nas organizações contemporâneas também já se comprovou. O componente definitivo para a mudança de referencial nessa virada de milênio, possivelmente seja a inclusão do espaço virtual no sistema social. O espaço virtual define uma terceira dimensão aos espaços possíveis - nem público, nem privado, porém ambos. As contradições e complexidades das organizações têm motivado inúmeras reflexões, porém, ainda sob a ótica do quadro de referência dualista ajustado a uma realidade multidimensional. A constatação de que as organizações contemporâneas são essencialmente constituídas por contradições e complexidades que desafiam os pressupostos sobre o que seja público ou privado remete para a questão central, anterior, maior e primordial: qual o limite que se quer entre o público e o privado para as novas formas urbanas que emergem nessa virada de milênio?

\section{Referências}

BORJA, Jordi. As Cidades e o Planejamento Estratégico: Uma Reflexão Européia e LatinoAmericana. In: FISCHER, Tânia. (Organizadora). Gestão Contemporânea. Cidades Estratégicas e Organizações Locais. $1^{a}$ ed. Rio de Janeiro, Fundação Getúlio Vargas, 1996. Parte II, cap.1, p. 79-99.

BRESSER PEREIRA, Luis Carlos. Cidadania e Res Publica: A Emergência dos Direitos Republicanos. In: Revista de Filosofia e Política - Nova Série. Vol I, 1997. Porto Alegre: Universidade Federal do Rio Grande do Sul, Departamento de Filosofia, 1997.

CAMPOS, Candido Malta. Os rumos da cidade: urbanismo e modernização em São Paulo. São Paulo: Editora SENAC São Paulo, 2002. 660p.

CAMPOS FILHO, Candido Malta. Reinvente seu bairro: caminhos para você participar do planejamento de sua cidade. São Paulo: Editora 34, 2003. 224p.

CAPPELLIN, Paola. Empresa, Empresários e Globalização. In: KIRSCHNER, Ana Maria; GOMES, Eduardo R.; CAPPELLIN, Paola. (Organizadores). As Organizações Empresariais Brasileiras e a Responsabilidade Social. Rio de Janeiro: Relume Dumará, 2002. 292p. 
CASTELLS, Manuel. A Sociedade em Rede. A Era da Informação: Economia, Sociedade e Cultura, Volume 1. Trad. Roneide Venancio Majer. $8^{a}$ ed. São Paulo: Editora Paz e Terra, 1999. 698p.

CAVALCANTI, Bianor Scelza. O Gerente Equalizador. Estratégias de gestão no setor público. Rio de Janeiro: Editora FGV, 2005. 280p.

COVAS, Mario. Apresentação. In: O Município no Século XXI: Cenários e Perspectivas. edição especial. São Paulo: Fundação Prefeito Faria Lima - CEPAM, 1999. p.III.

DAGNINO, Evelina. Sociedade civil, participação e cidadania: de que estamos falando? In Políticas de ciudadanía y sociedad civil en tiempos de globalización. Caracas: FACES, Universidad Central de Venezuela, pp. 95-110. 2004.

DRUCKER, Peter Ferdinand. A Sociedade Pós-Capitalista. $4^{\mathrm{a}}$ ed. Tradução: Nivaldo Montigelli Jr. São Paulo: Pioneira, 1993.

FISCHER, Tânia (Organizadora). Gestão Contemporânea. Cidades Estratégicas e Organizações Locais. Rio de Janeiro: Editora Fundação Getulio Vargas, 1996. 208p.

FORATTINI, Oswaldo Paulo. Qualidade de vida e meio urbano. A cidade de São Paulo, Brasil. Rev. Saúde Pública, Vol 25, nº 2, abril / 1991, p.75-86.

HITT, Michael A.; IRELAND. R. Duane e HOSKISSON, Robert E. Administração Estratégica: competitividade e globalização. Trad. José Carlos Barbosa dos Santos \& Luiz Antonio Pedroso Rafael. Revisão Técnica: Moacir Miranda Oliveira Junior. São Paulo: Pioneira Thomsom Learning, 2005. 550p.

KLINK, Jeroen e SANTOS, Roberto Elísio. Regionalismo e Reestruturação no Grande ABC Paulista: Uma Perspectiva Brasileira de Governança Metropolitana. Caderno de Pesquisa Pós-Graduação IMES. Estratégia como Exigência Empresarial. São Caetano do Sul, Ano 6, N. 11, p.12-22. $2^{\circ}$ semestre / 2004.

MEYER, Regina Maria Prosperi; GROSTEIN, Marta Dora; BIDERMAN, Ciro. São Paulo Metrópole. São Paulo: Editora da Universidade de São Paulo: Imprensa Oficial do Estado de São Paulo, 2004. 290p. 
MEYER, Regina Maria Prosperi. São Paulo: Uma Nova Abordagem. São Paulo: Associação Viva o Centro, 2000. 48p.

OLIVEIRA, Marcio Piñon de. Um Conceito de Cidadania para se Trabalhar a Cidade. GEOgraphia. Universidade Federal Fluminense. Rio de Janeiro. Ano I $-\mathrm{n}^{\mathbf{o}} 1$. janeirojunho, 1999.

OLSON, Mancur. A Lógica da Ação Coletiva. Os benefícios públicos e uma teoria dos grupos sociais. Tradução Fábio Fernandez. São Paulo: Editora da Universidade de São Paulo, 1999. (Clássicos 16). 201p.

RATTNER, Henrique. Sobre Exclusão Social e Políticas de Inclusão. Revista Espaço Acadêmico, Ano II, n. 18, Novembro de 2002. ISSN 1519.6186.

ROLNIK, Raquel. São Paulo, novo século: uma nova geografia? In: In: CAMPOS, Candido Malta; GAMA, Lucia Helena; SACCHETTA, Vladimir (organizadores). São Paulo, metrópole em trânsito: percursos urbanos e culturais. São Paulo: Editora SENAC São Paulo, 2004. pp.172-177.

SANCHEZ, Fernanda. A Reinvenção das Cidades Para Um Mercado Mundial. Chapecó (SC): UNOCHAPECÓ - Argos - Editora Universitária, 2003. 589p.

VIVA O CENTRO. O Centro de São Paulo ao seu alcance. Portal Institucional. Disponível em <http://www.vivaocentro.org.br>. Acesso: 05 jan. 2005.

WILHEIM, Jorge. O novo Plano Diretor Estratégico. In: CAMPOS, Candido Malta; GAMA, Lucia Helena; SACCHETTA, Vladimir (organizadores). São Paulo, metrópole em trânsito: percursos urbanos e culturais. São Paulo: Editora SENAC São Paulo, 2004. Capítulo 10. pp. 225-228.

Artigo recebido em 20/07/2005. Aprovado em 12/03/2005. 